\title{
Mia Öhman
}

\section{Tulitikkuja lainaamassa (1980) suomalais-neuvosto- liittolaisen elokuvayhteistyön huipentumana}

Tässä artikkelissa hahmotan viimeiseksi jäänyttä suomalais-neuvostoliittolaista yhteistuotantoelokuvaa Tulitikkuja lainaamassa (1980) osana Suomen ja Neuvostoliiton välistä monikymmenvuotista elokuvayhteistyötä. Elokuvan tekemistä taustoittaessani käsittelen osaa tulevan väitöskirjani Kosmos-Filmi. Sovexportfilm in Finland during the Cold War (1945-1980) aineistosta niin, että lukijalle syntyy käsitys Suomen ja Neuvostoliiton välisen elokuvayhteistyön luonteesta. Olen lukenut Sovexportfilmin Suomen edustajien raportteja 1940- ja 1950-luvuilta, yhteistuotantoelokuvien tuotantopapereita 1950-ja 1970-luvuilta ja tutustunut avainhenkilöiden kokemuksiin yhteistyöstä heidän kirjoittamansa ja heistä kirjoitetun perusteella. Tutkimusaineisto löytyi suurimmaksi osaksi Moskovasta Venäjän valtion kirjallisuuden ja taiteen arkistosta (RGALI) ja Helsingistä Kansallisen audiovisuaalisen instituutin (KAVI) kokoelmista. Näkökulmani aiheeseen on avartunut tutkimuksen myötä: Suomessa toimineen Neuvostoliiton elokuvamyyntimonopolin Sovexportfilmin yhteistyöprojektit ja sen tytäryhtiön Kosmos-Filmin elokuvalevitys eivät näyttäydykään erillisinä hankkeina, vaan ne liittyvät yhteen ja muodostavat selkeän jatkumon 1940-luvulta aina 1980-luvulle.

\section{Neuvostoideologiaa, idänkauppaa ja yhteistuotantoelokuvia}

Neuvostoliiton ulkomaille kohdistettu kulttuurityö oli ideologialähtöistä ja peräisin kommunistisen puolueen keskuskomitean ylimmistä kabineteista. Kulttuuriyhteistyö taas liittyi tiiviisti maiden väliseen kauppaan ja politiikkaan. Kaiken taustalla tuntuu aina olevan talous, ja selitys sille on, että poliittisia ja kulttuurisia suhteita on ylläpidetty ja kehitetty toimivan kaupan takaamiseksi.

Suomi oli sodan jälkeen Neuvostoliitolle tärkeä kauppakumppani, joka myöhemmin toimi myös idän ja lännen välisenä siltana: Suomen kautta Neuvostoliittoon oli mahdollista saada läntistä teknologiaa. Oli Neuvostoliitonkin etu, että Suomen kauppayhteydet toimivat niin itään kuin länteen. (Ks. Androsova 2002; Androsova 2019; Kochetkova 2017.)

Järjestelmällinen neuvostoelokuvien levittäminen Suomessa aloitettiin 1940-luvulla ja mukaan valjastettiin henkilöitä, joilla oli kokemusta aikaisemmastakin kulttuuriyhteistyöstä. Neuvostoelokuvan sodanjälkeinen uudistuminen ja suuntautuminen maailmanmarkkinoille alkoi näkyä 1950-luvulla viimeistään Kurjet lentävät -elokuvan (1957) menestyksen myötä. Vaikutus tuntui myös suomalaisessa elokuva- ja televisiotuotannossa viimeistään 1960-luvun lopulla; yksi merkittävä välittäjä oli Mikko Niskanen, joka oli saanut ohjaajanoppinsa Moskovan elokuvakoulussa. 
Yhteistuotantoelokuvat toimivat neuvostonäkökulmasta julistuksina, jotka oli suunnattu ensisijaisesti omalle kansalle. Niihin satsattiin, koska ne olivat ulkopoliittisesti tärkeitä - tämän ymmärsivät suomalaisetkin, vaikka elättelivät myös toivoa kansainvälisestä menestyksestä. Yhteistuotantoelokuviin sidottiin merkityksiä, niillä luotiin tietynlaista kuvaa valtioiden ja kansojen välisestä historiasta ja niiden julkaiseminen ajoitettiin sopivasti jonkin juhlapäivän yhteyteen.

Ensimmäinen yhteistuotantoelokuva oli Suomi-Filmin ja Mosfilmin yhteistuotanto, satuelokuvan ja erikoistehosteiden mestari Aleksandr Ptuškon ohjaama Sampo (1959). Se juhlisti kalevalaisin kuvin kapitalistisen ja sosialistisen valtion välistä kauppaa ja kulttuurivaihtoa osana Nikita Hruštšovin kauden rauhanomaista rinnakkaiseloa. Nyt tarkasteltuna Sampo on kansallisten ominaispiirteiden omaleimaisuuden pohdinnan ja toisaalta kulttuuristen risteävyyksien ja limittäisten historioiden keitos. Se yhdistää hämmentävällä tavalla ideatasolla Väinämöisen ja viikingit ja hyödyntää kerronnassa venäläisen kuvataiteen, runouden ja oopperan aineksia. Aikanaan se kuitenkin täytti suomalaisten Kalevala-tuntijoiden kriteerit tradition kunnioittamisesta.

Luottamus (1976) ei sitten ollutkaan kertomus Leninin seikkailuista Suomessa, kuten Väinö Mäkelä ja hänen poikansa Mauno Mäkelä olivat Fennada-Filmin ja Lenfilmin välisen yhteistuotantoelokuvan mielessään nähneet (Mäkelä \& Koukkunen 1996, 188), vaan tarkkaan rakennettu kuvaus suomalaisten itsenäistymisestä Venäjän vallan alta. Tekoprosessi synnytti suvantovaiheessa myös ajan henkeä kuvaavan YYA-juhladokumentin 25 vuotta ystävyyttä (1973) ${ }^{1}$, jossa Lenin oli niin ikään keskeisessä roolissa. Luottamuksen lopun ajallinen loikka vuoden 1917 sopimuksesta vuoden 1975 kesäiseen ETY-kokoukseen kohotti suomalaisten kulmakarvoja, mutta näin Brežnev sementoitiin Leninin perinnön jatkajaksi ja Leninin/Brežnevin rooli Suomen itsenäisyydessä välietapiksi matkalla maailmanrauhaan. Neuvostoliitossa ensi-ilta sijoittui sopivasti lähelle Brežnevin 70-vuotispäivää.

Kahden raskaan suurtuotannon perään tehtiin yllättäen aiheeltaan kevyt ja tyyliltään vanhahtava komedia Tulitikkuja lainaamassa. Yhteistyöstä tuskin oli vielä sovittu keväällä 1978, kun Suomi-Filmi ilmoitti tarttuvansa kesäteatteriklassikkoon, mutta toimitusjohtaja, kauppaneuvos Risto Orkon vihjailu Neuvostoliiton suuntaan antoi ymmärtää, että tiedusteluja oli tehty (Hytönen 1978, 19). Sammosta oli jo kulunut aikaa, ja Fennada-Filmi oli saanut haluamansa, kun Luottamus oli viimein valmistunut. Olisi jälleen Suomi-Filmin vuoro ylläpitää naapurisuhteita - tai hyötyä yhteistyöstä.

\section{Miksi Tulitikkuja lainaamassa valikoitui yhteistuotantoelokuvan aiheeksi?}

Maiju Lassilan veijariromaani Tulitikkuja lainaamassa (1910) näytti aikanaan suomalaisesta näkökulmasta virhetikiltä yhteistuotantoelokuvan aiheeksi - kuka nyt jaksaisi kiinnostua aikansa eläneestä maalaiskomediasta, jossa venäläiset yrittävät esittää suomalaisia. Lopputulos on koettu meillä muotopuoleksi ja vieraaksi, ja ainoa oikea elokuvaversio on edelleen se vuonna 1938 valmistunut, Yrjö Nortan ja Toivo Särkän ohjaama, jossa Aku Korhonen esittää Antti Ihalaista ja Uuno Laakso Jussi Vatasta kerta kaikkiaan mainiosti. (Ks. Räisänen 2003.) Arkistojen valossa Tulitikkuja lainaamassa ei valikoitunut sattumalta yhteistuotantoelokuvan aiheeksi: jäljet johtavat aina 1950-luvulle, jolloin Suomi-Filmin ja Suomessa toimineen Sovexportfilmin välinen yhteistyö alkoi.

Elokuvayhteistyö sai tuulta purjeisiin vuonna 1955, kun Neuvostoliiton kommunistisen puolueen keskuskomiteassa päätettiin laajentaa kulttuurisuhteita Suo-

1 Elokuvan suomalainen ohjaaja oli Matti Kassila. 
men kanssa. Samaan aikaan oli valmisteltu Porkkalan palauttamista, koordinoitu maiden välistä kauppaa, järjestetty vierailuja ja turistimatkoja puolin ja toisin - ja käyty alustavia neuvotteluja elokuvayhteistyöstä. (RGANI wiki.) Neuvostoliiton rauhanpuolustuskomitean delegaation johtaja A. [mahd. Anatoli] Sofronov raportoi osallistumisesta Suomessa järjestettyyn rauhanpuolustajien kongressiin ja Kalevalan päivän viettoon vuonna 1954. Neuvostoliiton rauhanpuolustuskomitean puheenjohtajan N. [mahd. Nikolai] Tihonovin saate on osoitettu Neuvostoliiton kommunistisen puolueen (NKP) keskuskomitean sihteerille Mihail Susloville. Liitteenä on "A. Rumjantsevin ja V. Stepanovin kirjelmä NKP:n keskuskomitealle ajalta 26.4.1954 koskien A. Sofronovin ehdotusta Suomen ja NL:n kulttuurisuhteiden laajentamisesta." (RGANI wiki: Luettelo 2, kohta 3.)

Huhtikuussa 1955 Suomen kommunistisen puolueen (SKP) keskuskomitea kirjelmöi NKP:n keskuskomitealle "koskien suomalais-neuvostoliittolaisten dokumenttielokuvien tuottamista Suomen ja NL:n elokuva-alan toimijoiden yhteistyön kehittämiseksi ja propagandan levittämiseksi suomalaisiin puolueorganisaatioihin" (RGANI wiki: Luettelo 3, kohta 60). Kesäkuussa 1955 SKP:n keskuskomitea lähetti NKP:n keskuskomitealle samaa asiaa koskevan kirjeen ja sen liitteenä Suomi-Neuvostoliitto-seuran pääsihteeri Toivo Karvosen kirjelmän "Suomen ja NL:n yhteistyömuodoista elokuva-alalla" sekä "Otteita Suomen lehdistöstä" (Uusi Suomi ajalta 8.6.1955)2, suomalaisten elokuvastudioiden toiminnasta. (RGANI wiki: Luettelo 3, kohta 63.) Seuraavat asiaa koskevat listatut dokumentit (ibid., kohta 64) ovat Neuvostoliiton kulttuuriministerin kirjelmä NKP:n keskuskomitealle 29.7.1955 "liittyen yhteisten dokumentti- ja taide-elokuvien ${ }^{3}$ tekemiseen sekä elokuvavaihtoon", liitteenä tiedot Maiju Lassilan ${ }^{4}$ ja Aleksis Kiven teoksista; 5.8.1955 NKP:n keskuskomiteaan lähetetty kirjelmä, jossa myönnetään lupa yhteisen dokumenttielokuvan tekemiseen suomalaisten kanssa; sekä viimeisenä "sähke NL:n suurlähettiläälle, aiheena Soveksportfilmin Suomen edustajan ohjeistaminen neuvottelujen aloittamiseksi suomalaisten elokuva-alan toimijoiden kanssa". Ensimmäinen yhteistyöelokuva oli siis "yhteinen dokumenttielokuva", joka olisi hyvin todennäköisesti Suomi-Filmin valmistama yhdeksänminuuttinen, Neuvostoliitossa kuvattu Terijokelaiset Kannaksella (1956).

Vuonna 1956 järjestettiin Neuvostoliiton aloitteesta suomalais-neuvostoliittolaiset filmiviikot, joiden aikana neuvosto-osapuoli teki aloitteen yhteistyöelokuvasta (Lehtisalo 2015, 59). Suomessa viikon järjestelyistä vastasi järjestelytoimikunta, jonka puheenjohtajana toimi opetusministeri Johannes Virolainen ja muina jäseninä konsuli Toivo Heikkilä ja toimittaja Yrjö Kaarne ulkoasiainministeriöstä ja suomalaisten elokuvayhtiöiden edustajat: toimitusjohtaja, maisteri Toivo Jalmari Särkkä (Oy Suomen Filmiteollisuus), toimitusjohtaja, insinööri Mauno Mäkelä (Oy Fennada-Filmi), Risto Orko ja filmipäällikkö Lars Åberg (Oy Suomi-Filmi) sekä toimitusjohtaja, kapteeni Klaus Holma (Oy Adams-Filmi). Neuvostovaltuuskunta vieraili Suomessa 12.-24.4.1956. Suomalainen elokuvaviikko piti järjestää Moskovassa, Leningradissa ja Kiovassa kesäkuun aikana. (Suomalais-neuvostoliittolaisten filmiviikkojen lehdistötiedote 1956. KAVI PAP-9.16 Su-Fi.) Se kuitenkin siirrettiin

2 Uudessa Suomessa kirjoitettiin saksalaisesta Peter Höferistä, joka matkusti Suomessa ja kuvasi kokoillan "kulttuurielokuvaa". Toinen juttu samalla sivulla koski Maunu Kurkvaaran yhteistuotantoa amerikkalaisen yhtiön kanssa. (US 1955, 7.) Toteutuessaan se olisi ollut ensimmäinen suomalainen pitkä värielokuva, mutta tuotantoyhtiö teki konkurssin. Kalliovuorilla kuvatun materiaalin Kurkvaara käytti elokuvassaan Perhosen uni (1985). (Toiviainen et al. 2002, 41.)

3 Tällä tarkoitetaan näytelmäelokuvaa, venäjäksi hudožestvennyi film.

4 Algot Untolan Maiju Lassila -nimellä kirjoitetut teokset kuvaavat suomalaista kansanluonnetta koomisessa valossa. 


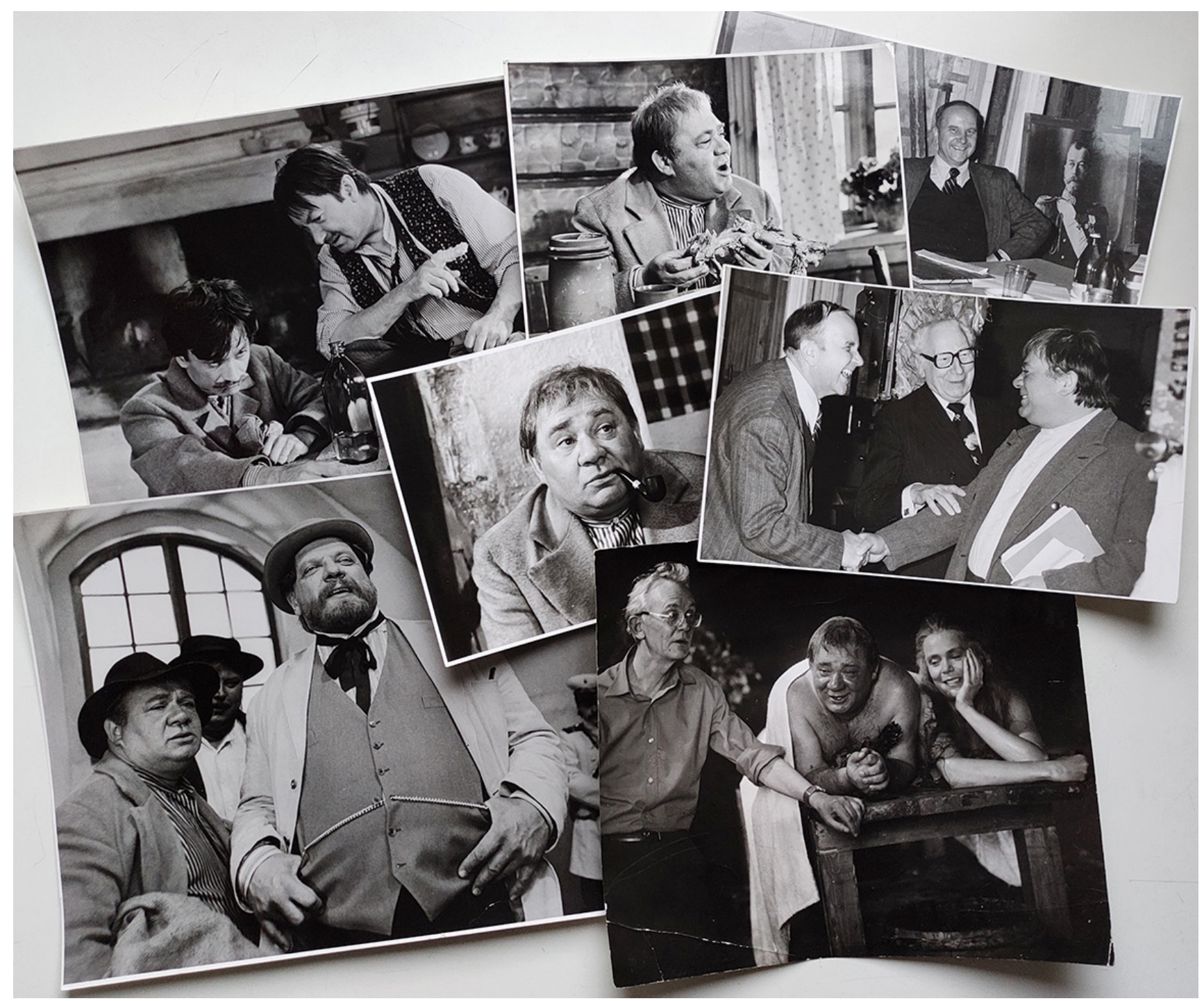

Kuva 1. Mosfilmin studiolla Tulitikkuja lainaamassa -elokuvan lavasteissa. Ylävasemmalta myötäpäivään Pekka Autiovuori ja Georgi Vitsin; Jevgeni Leonov; Jussi Kohonen; Kohonen ja Leonov kättelevät Risto Orkon edessä; Leonid Gaidai ohjaa Leonovia ja Rita Polsteria; Leonov ja Leo Lastumäki, keskellä Leonov.

Valokuvat: Valentin Kovalski. Kuvakollaasi: Mia Öhman.

marraskuulle suomalaisten toivomuksesta; kesä kannatti käyttää kuvauksiin (Lehtisalo 2015, 47). Suomalaiseen seurueeseen kuuluivat konsuli Toivo Heikkilä, Risto Orko, Mauno Mäkelä, Klaus Holma, T. J. Särkkä, Anneli Sauli, Hilkka Helinä ja Matti Oravisto (ibid., 46). Suomalaisen viikon valikoimaan kuului Yrjö Nortan ja T. J. Särkän vuonna 1938 ohjaama Tulitikkuja lainaamassa (ibid., 49).

\section{Monenlaista elokuvayhteistyötä}

Suomi-Filmin ja Sovexportfilmin välillä käytiin 1950-luvun mittaan neuvotteluja, joissa sovittiin toisaalta suomalaisista elokuvista, jotka haluttiin levitykseen Neuvostoliittoon, toisaalta neuvostoelokuvista, joiden levitysoikeudet Suomessa voitaisiin luovuttaa Suomi-Filmille. Kalevala-elokuva oli yksi neuvotelluista yhteistyöprojekteista, mutta samalla paperilla ehdotetaan vuonna 1957 valmistettavaksi 
toiseksi yhteistyöelokuvaksi aihetta Kimmon kosto, perustuen Eino Leinon balladiin. Jo valmisteilla olevan Aleksis Kivi -aiheen Nummisuutarit lisäksi Suomi-Filmi ehdottaa valmistavansa "periaatteessa samoin ehdoin" (tästä alla) elokuvan Nuori mylläri Maiju Lassilan aiheen pohjalta. Edelleen samassa paperissa mainitaan Loviisa-elokuvan (1946) levityssopimuksen neuvottelemisesta ja neuvostoelokuvien tekstittämisestä Suomessa Suomen levitykseen, ja mahdollisesti neuvostoelokuvien tekstittämisestä Suomessa muillekin kielille. (Yhteenveto neuvotteluista 1.12.1956 Moskovassa herra apulaisministeri Surinin kanssa. KAVI PAP-9.19 Su-Fi.) Leino-aihe ei ollut Sovexportfilmille mieleinen, mutta "suomalaisten ehdottamassa" Kalevalaaiheessa edettiin, ja Nuori mylläri voitiin toteuttaa, edelleen "samoin ehdoin" kuin Nummisuutarit (Neuvostoliiton Kulttuuriministeriön elokuvatuotannon päällikkö A. Fedorovin vastaus Orkon kirjeeseen 1.2.1957. KAVI PAP-9.16 Su-Fi).

Niskavuoren naiset -elokuvasta tehty sopimus valaisee, millä ehdoin Sovcolorelokuvat tehtiin. Sovexportfilm toimitti Suomi-Filmille Helsinkiin värifilminegatiivia ja muita tarvikkeita ja antoi kuvauksiin neuvonantajan, jonka palkan maksoi Sovexportfilm; matkat, päivärahat ja majoitusmenot maksoi Suomi-Filmi. Sovexportfilm kustansi materiaalin kehityksen ja valmiit filmikopiot. Vastineeksi Suomi-Filmi luovutti Sovexportfilmille elokuvan esitysoikeudet kuudeksi vuodeksi Neuvostoliitossa, Kiinan, Puolan, Romanian, Bulgarian, Albanian ja Mongolian kansantasavalloissa, Tšhekkoslovakian tasavallassa, Saksan demokraattisessa tasavallassa, Jugoslavian federatiivisessa kansantasavallassa, Korean kansandemokraattisessa tasavallassa ja Vietnamin demokraattisessa tasavallassa. (Suomi-Filmin ja Sovexportfilmin välinen sopimus Niskavuoren naiset -elokuvan tekemisestä ja oikeuksista 10.5.1957. KAVI PAP-9.19 Su-Fi.)

Suomi-Filmi olisi halunnut levittää Suomessa Ilja Muromets -elokuvaa ${ }^{5}$, mutta neuvosto-osapuoli ilmoitti, että sen kopioiminen on "teknisistä syistä mahdotonta" ja pyysi valitsemaan jonkin toisen pitkän elokuvan (Sovexportfilmin johtaja Davydovin vastaus Orkon kirjeeseen 1.2.1957. KAVI PAP-9.16 Su-Fi). Jussi Kohonen on aikaisemmin kertonut, että ensimmäinen Suomi-Filmin levittämä neuvostoelokuva oli Kurjet lentävät, jota Orko kuitenkin vierasti liian "venäläisenä". Kurjet lentävät esitettiin Suomi-Filmin teattereissa ${ }^{6}$, mutta yhtiö ei ottanut sitä vuokrattavakseen - mitä Orko sitten katui elokuvan osoittauduttua menestykseksi. (Öhman 2015, 73.) Nyt näyttäisi siltä, että ensimmäinen Suomi-Filmin levitykseen valitsema pitkä venäläiselokuva olisi ollut Vladimir Braunin ohjaus Malva - kohtalokas nainen (1956), jonka kanssa samassa lähetyksessä luovutettiin 28.1.1958 kaksi lyhytelokuvaa (kopioiden luovutuskuitti Kosmos-Filmiltä Suomi-Filmille 28.1.1958. KAVI PAP-9.19 Su-Fi). Kurjet lentävät oli voittanut Cannesin Kultaisen palmun toukokuussa 1958, ja se tuli teattereihin ensimmäisenä, syyskuussa 1958. Malvan ensi-ilta oli Astrassa pari vuotta myöhemmin, 24.2.1961 (Elonet).

1950-luvun yhteistyökuvioista piirtyy kuva vilkkaasta maiden rajan ylittävästä liikkeestä ja ajatuksenvaihdosta. Monenlaisesta elokuvaan liittyvästä yhteistyöstä erottuvat kokonaisuutena neljä Valentin Vaalan ohjaamaa Sovcolor-värielokuvaa: Nummisuutarit (1957), Nuori mylläri (1958), Niskavuoren naiset (1958) ja Nuoruus vauhdissa (1961). Hyvästä yrityksestä huolimatta Suomi-Filmin Nummisuutarit ei ehtinyt valkokankaalle ensimmäisenä suomalaisena pitkänä värielokuvana; voiton vei Suomen Filmiteollisuuden samana kesänä kuvaama Juha (1956). Toimitusjohtaja T. J. Särkän aihevalinta saattoi olla näpäytys venäläisille: Juhani Ahon tarinassa

5 Ilja Muromets eli Jättiläisten taistelu on Aleksandr Ptuškon ohjaus vuodelta 1956. Se sai Suomen ensi-iltansa Capitolissa 2.5.1958. (Elonet.)

6 Ensi-ilta 19.09.1958 Capitol ja Corona (Elonet). 
Uhtuan Shemeikka vie suomalaismieheltä vaimon. Juha tallentui Eastmancolorille ruotsalaisella AgaScope-laajakangasmenetelmällä (Uusitalo 1998, 206). Sammosta tehtiin versio vastaavalla neuvostoteknologialla (ibid., 207), ja sisälsi sekin koskenlaskukohtauksen. ${ }^{7}$

Suomalaisesta näkökulmasta Sampo valmistui hitaasti, mutta neuvosto-osapuolelle ensi-ilta vuonna 1959 tuskin tuli yllätyksenä ja sopi paremmin kuin mainiosti, ja olihan se myös Suomi-Filmin 40. juhlavuosi. Vuonna 1959 juhlittiin neuvostoelokuvan (1919-) ja Kalevalan (Uusi Kalevala 1849) tasapyöreitä ja uudelleenlanseerattiin Moskovan kansainväliset elokuvajuhlat. ${ }^{8}$ Kilpasarjassa esitettiin tuolloin Matti Kassilan ohjaama Punainen viiva (1959) ja tuomaristossa istui näyttelijätär Emma Väänänen, Valentin Vaalan Niskavuori-ohjausten Loviisa. ${ }^{9}$

\section{0-luvulta 1970-luvulle}

Juhasta lähtee mielenkiintoinen polku: siinä koskea laskenut Mikko Niskanen pääsi Moskovan elokuvakouluun ja sieltä palattuaan ohjasi ensi töikseen Suomen Filmiteollisuudelle Pojat (1962) ja Fennada-Filmille Sissit (1963) ja Hopeaa rajan takaa (1963) (Toiviainen 1999, 35-89). Niskasen ura suomalaisen yhteiskunnan murroksen välittäjänä huipentui Televisioteatterille toteutettuun Kahdeksaan surmanluotiin (1972). Viimeistään alkuvuodesta 1978, ehkä jo aikaisemmin, Niskanen jätti Kosmos-Filmissä toimineelle, hyvistä idänyhteyksistään tunnetulle Jussi Kohoselle luettavaksi Matti Pajulan käsikirjoituksen Tulitikkuja lainaamassa ja toivoi saatteessa, että "saataisiin jotenkin pää auki" (Matti Pajulan käsikirjoitus Tulitikkuja lainaamassa ja käsin kirjoitettu saate Jussille Mikolta. KAVI SC-259 Tulitikkuja lainaamassa [käsikirjoitusluonnoksia]). Risto Orkolle Niskanen lähetti 16.4.1978 päivätyn, allekirjoittamatta jääneen työsopimuksen, jossa hän toteaa yhteistyökuvioiden neuvostoliittolaisten kanssa olevan vielä auki, mutta tarjoutuu siitä huolimatta ohjaamaan elokuvan (Mikko Niskasen Risto Orkolle osoittama Käpy-Filmin ja Suomi Filmin välinen työsopimus 16.4.1978. KAVISC-259 Tulitikkuja lainaamassa [valmistusvaiheen oheismateriaalia]).

Kuten edellä mainitusta vuoden 1955 arkistodokumenttien listauksesta (RGANI wiki) näkyy, Maiju Lassilan teokset oli todettu jo tuolloin sopiviksi yhteistyöelokuvan aiheiksi, Aleksis Kiven tuotannon ohella. Tunnettu satiirikko Mihail Zoštšenko oli kääntänyt 1940-luvun lopulla venäjäksi teokset Tulitikkuja lainaamassa ja Kuolleista heränny $t^{10}$, joten kirjailija oli tunnettu Neuvostoliitossakin. Vuoden 1938 Tulitikkuja

7 Myös Fennada-Filmi teki värielokuvan ja valitsi ehkä muidenkin yhteistyökuvioiden toivossa neuvostomateriaalin. Kulkurin Masurkka (1958) jäi tappiolliseksi, ja yhtiön seuraava värielokuva valmistui vasta kymmenen vuotta myöhemmin (Uusitalo 1998, 207-208). Täällä Pohjantähden alla (1968) todennäköisesti vakuutti neuvostoliittolaiset lopullisesti yhtiön työn tasosta, ja yhteistuotanto nytkähti eteenpäin.

8 Moskovan kansainväliset elokuvajuhlat oli järjestetty ensimmäistä kertaa Sergei Eisensteinin johdolla vuonna 1935. Risto Orko oli tuolloin vieraana, ja juhlien ohjelmistossa oli Aleksandr Ptuškon ohjaama, nukkeanimaatiota näytelmäelokuvaan yhdistävä Uusi Gulliver (Novyi Gulliver, 1935). Elokuvajuhlat vakinaistettiin vuonna 1959, mistä vuoteen 1993 asti ne järjestettiin vuorovuosin Karlovy Varyn elokuvajuhlien kanssa. Nykyään molemmat festivaalit järjestetään vuosittain. Vuonna $1957 \mathrm{VI}$ Kansainvälisten Nuorisofestivaalien aikaan Moskovassa järjestettiin myös elokuvafestivaali teatteri Udarnikissa. Siellä Mikko Niskanen kuuli mahdollisuudesta opiskella ulkomaalaisena Moskovan elokuvakoulussa (Toiviainen 1999, 43).

9 Emma Väänänen oli tehnyt loistoroolin Vaalan elokuvassa Loviisa - Niskavuoren nuori emäntä (1946), joka myytiin neuvostolevitykseen 1957 (Neuvostoliiton Kulttuuriministeriön elokuvatuotannon päällikkö A. Fedorovin vastaus Orkon kirjeeseen 1.2.1957. KAVI PAP-9.16 Su-Fi). Väänänen esitti Loviisaa myös Vaalan elokuvissa Niskavuoren Heta (1952) ja Niskavuoren naiset (1958).

10 Kertomukset on julkaistu venäjäksi yhteisniteenä Moskovassa 1955. 
lainaamassa oli mukana vuoden 1956 filmiviikkojen ohjelmassa, ja Valentin Vaala ohjasi värielokuvaksi Lassilan näytelmän Nuori mylläri. Vuonna 1969 Helsingin Sanomissa julkaistiin APN:n uutinen, jonka mukaan "Maiju Lassilan tuotanto nauttii Neuvostoliitossa erityistä suosiota" ja "Neuvostoliittolaisilla televisionkatsojilla on ollut tilaisuus nähdä Leningradin televisiostudion esittämänä'Tulitikkuja lainaamassa' ja 'Kuolleista herännyt'" (HS 1969, 24). 1970-luvulle tultaessa Televisioteatteri tarttui Lassilaan ja toteutti ensiluokkaisesti satiirin Kuolleista herännyt (1975). Pirjo Honkasalo ja Pekka Lehto suunnittelivat kirjailijasta elämäkertaelokuvaa (Tulipää, 1980).

Tulitikkuja lainaamassa sopi mainiosti neuvostoliittolaisille. Elokuvan käsikirjoitus muokattiin moneen kertaan uudestaan, ja Niskasen sijaan suomalaiseksi ohjaajaksi ryhtyi Risto Orko. Rinnalla ohjasi neuvostokomedian konkari Leonid Gaidai, jonka aikaisempi Zoštšenko-ohjaus Ei voi olla totta! (Ne možet byt!, 1975) oli kerännyt Neuvostoliitossa lähemmäs 50 miljoonaa katsojaa.

Tulitikkuja lainaamassa valmistui Moskovan olympialaisiin 1980. Suomalaiset yritykset olivat olympialaisten tärkein tavarantoimittaja (Androsova 2019). Olympialaisiin mennessä ehti valmiiksi myös Helsingin keskustan Hotelli Presidentti. Sen alakertaan sijoittui hyvin varusteltu elokuvateatteri Kosmos, johon Sovexportfilmin isännöimän Kosmos-Filmin esitystoiminta siirtyi Capitolista. Tärkein vuosi oli kuitenkin 1979. Silloin Risto Orko täytti 80 vuotta ja sai presidentin myöntämän professorin arvonimen, Suomi-Filmi ja neuvostoelokuva täyttivät 60 vuotta ja Suomen ja Neuvostoliiton välisten laajempien kulttuurisuhteiden solmimisesta tuli kuluneeksi 25 vuotta. ${ }^{11}$ Matti Kassila kommentoi itänaapuriin päin kumartelua elokuvallaan Natalia (1979), jossa neuvostoliittolainen lehmä eksyy Suomeen. Elokuvan prologissa Kassilan esittämä henkilö katsoo pientä maata Neuvostoliiton kyljessä New Yorkista käsin, ja kieltämättä Natalian Suomi vaikuttaa hetkittäin varsin venäläiseltä. Ruotsalais-suomalaisella yhteistyöllä syntyi Herra Puntila ja hänen renkinsä Matti (1979). Tuuli kävi lännestä ja idästä.

Tulitikkuja lainaamassa sijoittuu autonomisen Suomen venäläistämisen aikaan. Suomalaiset maalaisjässikät Thalainen ja Vatanen örveltävät Join kaupungissa omien oikkujensa ja tarpeidensa mukaan ja viittaavat kintaalla viralliselle järjestykselle. Suomalaiset tunnetaan Venäjällä periaatteessa hyväntahtoisina, tyhminä tyyppeinä, jotka ovat hitaita, mutta kovia pitämään puoliaan (ks. Susiluoto 2006) - ja saivat Pietari Suuren rakentamaan kaupungin suolle (Haapasalo 2002).

1970-luvun lopulla rajat ylittävää yhteistyötä oli tehty jo kymmeniä vuosia, ja siinä ohessa nähty kaikenlaista. Tässä voikin olla avain elokuvaan. Herkkupalat säästän väitöskirjaan, mutta läpikäymäni aineiston perusteella esitän ajatuksen, että Tulitikkuja lainaamassa -yhteistuotanto on osoitus venäläisten elokuvavirkamiesten huumorintajusta. He olivat seuranneet suomalaista elokuvaväkeä riittävästi ymmärtääkseen, ettei Maiju Lassila ollut keksinyt hahmojaan, kuvaillut vain tarkkaan maanmiehiään. Tulitikkuja lainaamassa on venäläinen katse naapuriin - oodi suomalaiselle kansanluonteelle, lempeä nauru noille kummallisille mutta hyödyllisille tyypeille.

11 Suomessa nähtiin syksyllä 1979 Warren Beattyn kuvausryhmä ja valtaisia avustajajoukkoja tekemässä elokuvaa Punaiset (Reds, USA 1981), joka perustuu John Reedin teokseen Kymmenen päivää jotka järisyttivät maailmaa - siis samaan kirjaan kuin Sergei Eisensteinin vallankumousjuhlaelokuva Lokakuu (Oktjabr, 1927). Helsinki esitti Pietaria. Neuvostovastaisku, Sergei Bondartšukin ohjaama kaksiosainen, myös Reedin teoksiin perustuva Punaiset kellot (Krasnyje kolokola, 1982) oli jo tekeillä. Se tehtiin neuvostoliittolais-italialais-meksikolaisena yhteistuotantona. 


\section{Lähteet}

Androsova, Tatjana (2002) Suomen ja Venäjän/Neuvostoliiton kauppapoliittiset suhteet 1944-1962. Ennen ja nyt 2.1. Historiallinen yhdistys.

Androsova, Tatjana (2019) Poslevojennyje otnoshenija SSSR i Finljandii: torgovlja i politika (Neuvostoliiton ja Suomen sodanjälkeiset suhteet: kauppa ja politiikka). 20.3. Venäjän valtion historia sivustolla statehistory.ru. Saatavilla: <https://statehistory.ru/5962/Poslevoennye-otnosheniya-SSSR-i-Finlyandiitorgovlya-i-politika/> (linkki tarkistettu 8.12.2021).

Elonet. Saatavilla: <https://elonet.finna.fi/>.

Haapasalo, Ville (2002) Pietari - väärinymmärretty kaupunki. Idäntutkimus 9:4, 50-51. Saatavilla: <https://journal.fi/idantutkimus/article/view/83134> (linkki tarkistettu 8.12.2021).

Helsingin Sanomat (HS): Maiju Lassila suosittu Neuvostoliitossa. 31.8.1969, s. 24.

Hytönen, Mattiesko (1978) Elokuvasökön viimeisin nokitus. Miten Suomi-Filmi sai potin. Helsingin Sanomat 16.6., s. 19.

Kansallinen audiovisuaalinen instituutti (KAVI)

Kochetkova, Elena (2017) The Soviet Forestry Industry in the 1950s and 1960s: A Project of Modernization and Technology Transfer from Finland. Academic dissertation. Faculty of Social Sciences, Economic and Social History, University of Helsinki.

Lehtisalo, Anneli (2015) "Ihmisten onneen pyrkivällä taiteella ei ole raja-aitoja". Kansainvälistyvä elokuvakulttuuri ja Suomalais-neuvostoliittolaiset filmiviikot 1956 kulttuuridiplomatiana. Lähikuva 28:3, 38-63.

Mäkelä, Mauno ja Kalevi Koukkunen (1996) Kerrankin hyvä kotimainen: elokuvatuottajan muistelmat. Porvoo: WSOY.

RGANI wiki. Venäläiset tietokannat: Luettelo Moskovan RGANI-arkistossa säilytettävistä Suomea koskevista asiakirjoista. Saatavilla: <http://wiki.narc.fi/vtk/index.php/RGANI> (linkki tarkistettu 8.12.2021).

Räisänen, Kimmo (2003) "Tehkää vain, kyllä valtio maksaa!" - Suomalais-neuvostoliittolaiset yhteistuotantoelokuvat. Oulun yliopisto, historian laitos. Aate- ja oppihistorian pro gradu -tutkielma.

Susiluoto, Ilmari (2006) Takaisin Neuvostoliittoon: venäläisen huumorin täydellistäminen. Helsinki: Ajatus.

Toiviainen, Sakari et al. (2002) Suomen kansallisfilmografia, osa 10. Edita/SEA.

Toiviainen, Sakari (1999) Tuska ja hurmio. Mikko Niskanen ja hänen elokuvansa. Helsinki: SKS.

Uusi Suomi (US) 8.6.1955, s. 7.

Uusitalo, Kari (1998) Suomalaisen värielokuvan synty. Suomen kansallisfilmografia, osa 7. Edita/SEA, 205-209.

Öhman, Mia (2015) Jussi Kohonen puhuu. Haastattelu. Lähikuva 28:3, 70-81. 